\title{
PEMBINAAN TATA BAHASA INDONESIA PADA ADMINISTRASI SURAT-MENYURAT DAN RUANG PUBLIK
}

\author{
Tri Pujiatna ${ }^{1}$, Dede Endang Mascita ${ }^{2}$, Yusida Gloriani ${ }^{3}$ \\ ${ }^{1}$ FKIP Universitas Swadaya Gunung Jati \\ email: tpujiatna@gmail.com \\ ${ }^{2}$ FKIP Universitas Swadaya Gunung Jati \\ email: dedenmas@gmail.com \\ ${ }^{3}$ FKIP Universitas Swadaya Gunung Jati \\ email: yusidagloriani68@gmail.com
}

\begin{abstract}
The language of use, mostly Indonesian, in the general public (lay on the subject of Indonesian grammar) is not optimal. This happens because the rules of Indonesian language are not yet good and effective. These discrepancies are often found in all fields, such as public spaces and administrative institutions (correspondence). This needs to be understood. Therefore, efforts are needed to improve it. One way of coaching and socializing about the use of Indonesian. Efforts to foster and develop Indonesian language, both in their position as national languages and languages, need to be increased, before the global era and free trade era as it is today. This replaces the position and function of the Indonesian language to become more stable so that the Indonesian language can become a means of modern communication and be able to place itself parallel with other modern languages in the world. Through the Tri Dharma program of Higher Education, Community Service, the fostering and dissemination of Indonesian language aims to provide insight and understanding of the use of Indonesian language that is good and right. In addition, a language development and assistance program is provided by the Language Board of the Ministry of Education and Culture. This needs to be done so that people can prioritize the use of Indonesian.
\end{abstract}

Keywords: Indonesian grammar; letters administrative grammar; grammar of public spaces

\begin{abstract}
ABSTRAK
Pengunaan bahasa terutama bahasa Indonesia, pada masyarakat umum (awam ihwal tata bahasa Indonesia) belum maksimal. Hal ini terjadi karena belum dikuasainya kaidah bahasa Indonesia yang baik dan efektif. Ketidaksesuaian tersebut sering ditemukan pada segala bidang, misalnya ruang publik serta administrasi lembaga (surat-menyurat). Hal ini perlu dimaklumi. Oleh karena itu, perlu adanya suatu usaha untuk memperbaikinya. Salah satu dengan cara pembinaan dan sosialisasi tentang penggunaan bahasa Indonesia. Upaya pembinaan dan pengembangan bahasa Indonesia, baik dalam kedudukannya sebagai bahasa nasional maupun bahasa negara, perlu terus ditingkatkan, terlebih pada era global dan era perdagangan bebas seperti sekarang ini. Hal itu dimaksudkan agar kedudukan dan fungsi bahasa Indonesia tersebut menjadi semakin mantap sehingga bahasa Indonesia dapat
\end{abstract}


menjadi sarana komunikasi yang modern dan mampu menempatkan diri sejajar dengan bahasa-bahasa modern yang lain di dunia. Melalui program Tri Dharma Perguruan Tinggi, Pengabdian Kepada Masyarakat, pembinaan serta sosialisasi bahasa Indonesia ini bertujuan untuk memberikan wawasan dan pemahaman terhadap penggunaan bahasa Indonesia yang baik dan benar. Selain itu, membantu program pembinaan dan pengembangan bahasa dari Badan Bahasa di bawah Kementerian Pendidikan dan Kebudayaan. Hal ini perlu dilakukan agar masyarakat untuk mengutamakan penggunaan bahasa Indonesia.

Kata Kunci: tata bahasa Indonesia; tata bahasa administrasi surat; tata bahasa ruang publik

\section{PENDAHULUAN}

Bahasa merupakan bentuk kreativitas antara pemakai dengan lingkungannya. Bahasa berfungsi sebagai alat untuk komunikasi, baik tulis maupun verbal. Sebagai alat komunikasi, bahasa memiliki peran yang sangat penting dan multiperan dalam berbagai lini kehidupan. Selain itu, politik bahasa Nasional merupakan kebijakan nasional di bidang bahasa, yaitu kebijakan-kebijakan yang berkaitan dengan keberadaan bahasa yang ada di Indonesia. Bahasa yang dimaksud adalah bahasa Indonesia, bahasa daerah, dan bahasa asing yang digunakan dalam segala aspek kehidupan di masyarakat Indonesia.

Bahasa Indonesia sebagai wahana komunikasi dalam hubungan sosial maupun formal. Oleh karena itu, sudah seharusnya pemakai bahasa Indonesia mulai dari tingkat dasar sampai dengan tingkat perguruan tinggi menunjukkan kemantapan dalam berbahasa Indonesia sebagai bahasa nasional. Tujuan pendidikan dan pengajaran bahasa Indonesia adalah membina keterampilan peserta didik mampu berbahasa Indonesia dengan baik dan benar dalam upaya meningkatkan mutu masyarakat Indonesia sebagai bekal mengahadapi kehidupan masa kini ke masa yang akan datang.

Pengunaan bahasa, terutama bahasa Indonesia, pada masyarakat umum (awam inwal tata bahasa Indonesia) belum maksimal. Hal ini karena belum dikuasinya kaidah bahasa Indonesia yang baik dan efektif. Ketidaksesuaian tersebut sering ditemukan pada segala bidang, misalnya ruang publik serta administrasi lembaga (surat-menyurat). Oleh karena itu, perlu adanya suatu usaha untuk memperbaikinya. Salah satu dengan cara pembinaan dan sosialisasi tentang penggunaan bahasa Indonesia.

Upaya pembinaan dan pengembangan bahasa Indonesia, baik dalam kedudukannya sebagai bahasa nasional maupun bahasa negara, perlu terus ditingkatkan, terlebih pada era global dan era perdagangan bebas seperti sekarang ini. Hal itu dimaksudkan agar kedudukan dan fungsi bahasa Indonesia tersebut menjadi semakin mantap sehingga bahasa Indonesia dapat menjadi sarana komunikasi yang modern dan mampu menempatkan diri sejajar dengan bahasa-bahasa modern yang lain di dunia. Sekait dengan program pengabdian kepada masyarakat, kegiatan pembinaan bahasa Indonesia ini merupakan salah satu upaya yang berhubungan dengan 
pelaksanaan kegiatan penyebaran bahasa Indonesia ke khalayak sasaran. Upaya yang dilakukan dalam program pembinaan tata bahasa pada administrasi surat-menyurat dan ruang publik dengan cara penyuluhan, sosioalisasi, dan pelatihan.

Sebelum melaksanakan kegiatan pembinaan ini, tim pengabdian kepada masyarakat melakukan studi awal berupa analisis penggunaan tata bahasa Indonesia pada administrasi surat-menyurat dan ruang publik dan hasilnya ditemukan beberapa kekeliruan dalam penerepan kaidah bahasa Indonesia, yaitu terutama berupa ejaan dan struktur bahasa Indonesia. Hal ini didasarkan dari hasil wawancara dengan mitra bahwa para perangkat desa belum menguasai inwal tata bahasa Indonesia. Selain itu, belum adanya kegiatan pembinaan dan sosialisai tentang penggunaan bahasa Indonesia yang baik dan benar bagi perangkat desa dan masyarakat Desa Kasugengan Lor.

Melalui program Tri Dharma Perguruan Tinggi, Pengabdian Kepada Masyarakat (PKM), pembinaan serta sosialisasi bahasa Indonesia ini diharapkan memberikan edukasi kepada masyarakat inwal tata bahasa Indonesia dalam kegiatan administrasi surat-menyurat dan ruang publik. Di samping itu, kegiatan ini memberikan wawasan dan pengetahuan tentang penggunaan bahasa Indonesia bagi perangkat desa dan masyarakat setempat. Terutama bagi perangkat Desa Kasugengan Lor yang notabene sering menggunakan bahasa Indonesia tulis dalam kegiatan administrasi surat-menyurat dan ruang publik. Hal ini dimaksudkan agar komunikasi tulis yang digunakan berjalan dengan efektif dan dapat dirasakan manfaatnya secara langsung bagi masyarakat. Menulis memerlukan kecermatan dan ketelitian serta tulisannya dapat dimengerti orang lain yang membaca (Nurhayatin, Inggriyani, \& Ahmad, 2018).

Adapun tujuan dan manfaat dari kegiatan pengabdian ini yaitu: (1) memberikan edukasi serta membiasakan mengunakan bahasa Indonesia yang baik dan benar kepada masyarakat dan perangkat Desa Kasugengan Lor, Kecataman Depok Kabupaten Cirebon terutama dalam penggunaan tata bahasa pada administrasi surat dan ruang publik; (2) Meningkatkan kemampuan penggunaan tata bahasa bahasa Indonesia pada administrasi surat-menyurat dan ruang publik pada perangkat Desa Kasugengan Lor Kecamatan Depok, Kabupaten Cirebon.

Program PKM ini mengacu pada Undang-Undang Nomor 24 Tahun 2009 tentang Bendera, Bahasa dan Lambang Negara, serta Lagu Kebangsaan. Hal ini menjelaskan bahwa penggunaan bahasa Indonesia menempatkan posisinya paling atas dari pada bahasa lainnya. Selain itu, didasarkan pada program kerja Badan Bahasa. Sehingga perlu adanya pengawasan dan pembinaan bahasa Indonesia pada masarakat umum. Adapun pasal dan ayat yang menjelaskan tentang penggunaan bahasa Indonesia sebagai berikut. 
1. Pasal 25, ayat (3): Bahasa Indonesia sebagai bahasa resmi negara sebagaimana dimaksud pada ayat (1) berfungsi sebagai bahasa resmi kenegaraan, pengantar pendidikan, komunikasi tingkat nasional, pengembangan kebudayaan nasional, transaksi dan dokumentasi niaga, serta sarana pengembangan dan pemanfaatan ilmu pengetahuan, teknologi, seni, dan bahasa media massa.

2 Pasal 31, ayat (1): Bahasa Indonesia wajib digunakan dalam nota kesepahaman atau perjanjian yang melibatkan lembaga negara, instansi pemerintah $\mathrm{Rl}$, lembaga swasta Indonesia atau perseorangan warga negara Indonesia; Ayat (2): Nota kesepahaman atau perjanjian sebagaimana dimaksud pada ayat (1) yang melibatkan pihak asing ditulis juga dalam bahasa nasional pihak asing tersebut dan/atau bahasa Inggris.

3. Pasal 32, ayat (1): Bahasa Indonesia wajib digunakan dalam forum yang bersifat nasional atau forum yang bersifat internasional di Indonesia; Ayat (2) Bahasa Indonesia dapat digunakan dalam forum yang bersifat internasional di luar negeri.

4. Pasal 33, ayat (1) Bahasa Indonesia wajib digunakan dalam komunikasi resmi di lingkungan kerja pemerintah dan swasta.

5. Pasal 34, Bahasa Indonesia wajib digunakan dalam laporan setiap lembaga atau perseorangan kepada instansi pemerintahan.

6. Pasal 36 ayat (1) Bahasa Indonesia wajib digunakan dalam nama geografi di Indonesia; ayat (2) Nama geografi sebagaimana dimaksud pada ayat (1) hanya memiliki 1 (satu) nama resmi; ayat (3) Bahasa Indonesia wajib digunakan untuk nama bangunan atau gedung, jalan, apartemen atau permukiman, perkantoran, kompleks perdagangan, merek dagang, lembaga usaha, lembaga pendidikan, organisasi yang didirikan atau dimiliki oleh warga negara Indonesia atau badan hukum Indonesia; ayat (4) Penamaan sebagaimana dimaksud pada ayat (1) dan ayat (3) dapat menggunakan bahasa daerah atau bahasa asing apabila memiliki nilai sejarah, budaya, adat istiadat, dan/atau keagamaan.

7. Pasal 37 ayat (1) Bahasa Indonesia wajib digunakan dalam informasi tentang produk barang atau jasa produksi dalam negeri atau luar negeri yang beredar di Indonesia; (2) Informasi sebagaimana dimaksud pada ayat (1) dapat dilengkapi dengan bahasa daerah atau bahasa asing sesuai dengan keperluan.

8. Pasal 38 ayat (1) Bahasa Indonesia wajib digunakan dalam rambu umum, penunjuk jalan, fasilitas umum, spanduk, dan alat informasi lain yang merupakan pelayanan umum; (2) Penggunaan Bahasa Indonesia sebagaimana dimaksud pada ayat (1) dapat disertai bahasa daerah dan/atau bahasa asing. 
Administrasi lembaga yang dimaksud pada program ini menekankan pada kegiatan surat-menyurat. Surat merupakan salah satu bentuk komunikasi tulis baik antarindivu, antarkelompok, individu dengan individu, individu dengan kelompok ataupun sebaliknya. Hal ini sejalan dengan pendapat Barthos (2009:36) bahwa surat adalah salah satu alat komunikasi tertulis yang berasal dari satu pihak dan ditujukan kepada pihak lain untuk menyampaikan warta. Sebagai salah satu bentuk komunikasi, surat tidak akan lepas dari penggunaan bahasa. Dalam melakukan tugasnya, penggunaan tata bahasa Indonesia pada adminstrasi lembaga memerlukan suatu pemikiran yang labih agar maksud yang ingin dicapai dapat diterima dengan baik. Oleh karena itu, penguasaan konsep surat penyusunan surat harus dipahami oleh pembuatnya. Konsep tersebut berupa bentuk surat dan tata bahasa surat.

Menurut Kusumawijaya (2006) ruang publik merupakan ruang atau lahan, tempat masyarakat dapat melakukan kegiatan publik fungsional maupun kegiatan sampingan lainnya yang dapat mengikat suatu komunitas, baik melalui kegiatan sehari-hari atau kegiatan berkala. Hal ini menjelaskan bahwa ruang publik dapat digunakan oleh siapa saja dalam berbagai aktivitas harian maupun berkelanjutan. Pada ruang publik memungkinkan terjadinya berbagai macam aktivitas yang melibatkan berbagai unsur. Penggunaan bahasa di ruang publik harus menggunakan bahasa Indonesia yang baik dan benar sesuai dengan fungsi dan situasinya (Hendrastuti, 2015).

Penggunaan bahasa Indonesia pada administrasi surat dan ruang publik, penulis/pengonsep membutuhkan suatu pemahaman dan keterampilan yang mantap. Untuk dapat menerapkan dengan baik, perlu suatu usaha yaitu memilih kata atau diksi. Pilihan kata dalam penggunaan bahasa berdampak pada kesan dan makna yang akan ditimbulkan, Ketepatan pemilihan kata berkaitan dengan menggunakan kata sesuai dengan makna yang ingin dicapai (Keraf, 2005:85). Hal ini menjelaskan bahwa memilih kata akan berkaitan dengan suasana dan lingkungan berbahasa.

\section{METODE PELAKSANAAN}

Pelaksanaan kegiatan ini diadakan bagi perangkat desa dan masyarakat Kasugengan Lor Kabupaten Cirebon. Untuk mengatasi permasalahan mitra di atas, maka perlu adanya suatu metode atau cara. Program Pengabdian Kepada Masyarakat (PKM) ini menggunakan metode diskusi dialogis. Metode yang digunakan meliputi penyampaian materi oleh narasumber dan diselingi dengan diskusi dan tanya jawab dengan peserta (Surachman, 2016).

Adapun prosedur yang dilakukan sebagai berikut:

1. Melakukan studi awal berupa analisis situasi, terutama penggunaan tata bahasa pada administrasi surat-menyurat dan ruang publik dengan cara mengamati surat-surat yang dibuat oleh perangkat desa dan mengamati penggunaan bahasa pada ruang publik seperti pengumuman, spanduk, ucapan, dan lain-lain, 
2. Mengadakan koordinasi dengan Kepala Desa Kasugengan Lor, Kecamatan Depok, Kabupaten Cirebon untuk menentukan waktu pelaksanaan kegiatan, serta khalayak sasaran.

3. Pelaksanaan kegiatan pengabdian berupa pembinaan tata bahasa Indonesia pada administrasi surat dan pada ruang publik di lembaga pemerintahan Desa Kasugengan Lor.

\section{HASIL DAN PEMBAHASAN}

\section{Kaidah Penggunaan Tata Ejaan dalam Administrasi Surat dan Ruang} Publik.

Ejaan merupakan aturan tentang tata cara dalam menuliskan lambang-lambang bahasa tulis yang berkaitan dengan tata tulis huruf, kata, tanda baca sebagai sarananya (Pujiatna, 2018). Penggunaan ejaan dalam administrasi surat dan ruang publik ini perlu ditaati. Hal ini dimaksudkan agar adanya keseragaman bentuk pada penulisannya.

Beberapa temuan penggunaan tata bahasa pada administrasi surat dan ruang publik berupa kesalahan penulisan ejaan bahasa Indonesia. Berikut kekeliruan penggunaan ejaan serta saran perbaikan yang berpedoman pada Pedoman Umum Ejaan Bahasa Indonesia (Badan Pengembangan dan Pembinaan Bahasa, 2016);

Tabel 1.

Kaidah Penggunaan Tata Ejaan

\begin{tabular}{|c|c|c|}
\hline No. & $\begin{array}{c}\text { Kekeliruan Penulisan } \\
\text { Ejaan }\end{array}$ & Perbaikan kesalahan \\
\hline 1 & Antri & Antre \\
\hline 2 & Diatas & di atas \\
\hline 3 & di himbau & dihimbau \\
\hline 4 & $\mathrm{~s} / \mathrm{d}$ & s.d. \\
\hline 5 & $a / n$ & a.n. \\
\hline 6 & Sda & s.d.a. \\
\hline 7 & Jum'at & Jumat \\
\hline 8 & do'a & doa \\
\hline 9 & Haturkan & sampaikan \\
\hline 10 & Terimakasih & terima kasih \\
\hline 11 & $\operatorname{tgl}$ & tanggal \\
\hline 12 & pasca banjir & pascabanjir \\
\hline 13 & Dimana & di mana \\
\hline 14 & Shalat & salat \\
\hline 15 & Dhuhur & zuhur \\
\hline 16 & Ashar & asar \\
\hline 17 & Wudlu & wudu \\
\hline 18 & Ustad & ustaz \\
\hline 19 & Ramdhan & ramadan \\
\hline 20 & Mushola & musala \\
\hline 21 & Legalisir & legalisasi \\
\hline 22 & dari pada & daripada \\
\hline 23 & jam* & pukul \\
\hline
\end{tabular}




\section{Keefektifan Penggunaan Bahasa Dalam Administrasi Surat dan Ruang Publik.}

Keefektifan sebuah kalimat adalah kalimat yang mampu menyampaikan pesan dengan baik dengan memperhatikan komposisi unsur-unsur pembangun kalimat. Kalimat dikatakan efektif apabila tepat dalam memilih kata dan tidak bertele-tele. Ketepatan pilihan kata berpengaruh terhadap keefektifan sebuah kalimat (Saputra dkk, 2016). Hal ini sependapat dengan Hendrastuti (2015) menjelaskan bahwa pilihan kata dalam penggunaan bahasa berpengaruh pada kesan dan makna yang ditimbulkan.

Beberapa temuan ketidakefektifan penggunaan bahasa pada administrasi surat-menyurat dan ruang publik. Berikut ketidakefektifan dalam penggunaan bahasa pada adminitrasi surat-menyurat dan ruang publik serta perbaikan yang dilakukan.

Tabel 2.

Keefektifan Penggunaan Bahasa

\begin{tabular}{|c|c|c|}
\hline No & Kekeliruan & Analisis dan perbaikan \\
\hline 1 & Cirebon, 20 Januari 2019 & $\begin{array}{l}\text { Penulisan nama kota Cirebon pada } \\
\text { tanggal surat resmi dengan } \\
\text { menggunakan kop/kepala surat tidak } \\
\text { perlu ditulis. Hal ini merupakan } \\
\text { pemborosan karena di dalam kop/kepala } \\
\text { surat sudah tercantum nama kota di } \\
\text { mana surat itu dibuat. } \\
\text { Perbaikan : } \\
\text { 20 Januari } 2019\end{array}$ \\
\hline 2 & Kepada Yth. & $\begin{array}{l}\text { Penggunaan kata Kepada dan Yth pada } \\
\text { alamat surat yang dituju tidak perlu } \\
\text { digunakan secara bersamaan. Hal ini } \\
\text { merupakan pemborosan karena kata } \\
\text { kepada dan Yth. Memiliki tingkat yang } \\
\text { sama. Oleh karena itu, pengosep atau } \\
\text { pengetik surat harus memilih salah } \\
\text { satunya. } \\
\text { Perbaikan : } \\
\text { Kepada atau Yth. }\end{array}$ \\
\hline 3 & $\begin{array}{l}\text { Selamat Hari Jadi Kabupaten } \\
\text { Cirebon Ke-537 }\end{array}$ & $\begin{array}{l}\text { Penulisan struktur kalimat pada Selamat } \\
\text { Hari Jadi Kabupaten Cirebon Ke-537 } \\
\text { tidak logis. Secara makna penunjukan } \\
\text { urutan angka ke-537 pada Kabupaten } \\
\text { Cirebon Ke-537 merujuk pada jumlah } \\
\text { Kabupaten Cirebon yang berjumlah } \\
\text { sebanyak } 537 \text {. Dalam kalimat tersebut, } \\
\text { hal yang dimaksud adalah hari jadi/hari } \\
\text { ulang tahunnya. Namun, susunannya } \\
\text { yang keliru } \\
\text { Perbaikan : } \\
\text { Selamat Hari jadi Ke-537 Kabupaten } \\
\text { Cirebon }\end{array}$ \\
\hline
\end{tabular}


Bagi para jama'ah yang membawa alat komunikasi harap dimatikan.
Penulisan himbauan Bagi para jamaah yang membawa alat komunikasi harap dimatikan tidak logis dan cenderung sadis. Di dalam kalimat tersebut ajakannya adalah mematikan para jamaahnya, bukan pada alat komunikasi yang dibawa oleh para jamaah. Himbauan tersebut dimaksudkan agar menonaktifkan alat komunikasi yang dibawa agar tidak mengganggu kekhusyukan dalam menjalankan ibadah salat.

Perbaikan :

Mohon nonaktifkan alat komunikasi Anda ketika sedang salat.

Atau

Mohon alihkan alat komunikasi Anda ke modus getar ketika sedang salat

\section{KESIMPULAN}

Simpulan pada pengabdian kepada masyarakat ini bahwa dengan adanya program pembinaan tata bahasa Indonesia pada administrasi suratmenyurat dan ruang publik memberikan sumbangsih ilmu pengetahuan kepada perangkat desa serta masyarakat tentang penggunaan bahasa Indonesia yang baik dan benar sesuai dengan fungsi dan situasinya. Selain itu, program pembinaan tata bahasa Indonesia ini merupakan salah satu wujud Tri Dharma Perguruan Tinggi yang harus dilaksanakan sehingga keberadaan kami sebagai akademisi dapat dirasakan manfaat keilmuan yang dimiliki bagi masyarakat setempat.

\section{UCAPAN TERIMA KASIH}

Program Pengabdian Kepada Masyarakat (PKM) ini tidak akan berjalan dengan baik apabila tidak ada dukungan dari berbagai pihak. Terima kasih kepada Lembaga Pengabdian Masyarakat (LPM) Universitas Swadaya Gunung Jati yang telah mendanai program ini. Terima kasih untuk Kepala Desa, perangkat desa dan masyarakat Desa Kasugengan Lor Kecamatan Depok Kabupaten Cirebon sebagai mitra dalam kegiatan ini.

\section{DAFTAR RUJUKAN}

Badan Pengembangan dan Pembinaan Bahasa. (2016). Pedoman Umum Ejaan Bahasa Indonesia. Jakarta: Kementerian Pendidikan dan Kebudayaan.

Bartos, B. (2009). Manajemen Kearsipan. Jakarta: Bumi Aksara.

Keraf, G. (2005). Diksi dan Gaya Bahasa. Jakarta: Gramedia.

Hendrastuti, R. (2015) Variasi Penggunaan Bahasa Pada Ruang Publik di Kota Surakarta. Kandai. 11 (1), 29-43

Kusumawijaya, M. (2006). Kota Rumah Kita. Jakarta: Borneo. 
Nurhayatin, T., Feby I., Arifin A. (2018). Analisis Kefektifan Penggunaan Kalimat dalam Karya Tulis Ilmiah Mahasiswa Pendidikan Guru Sekolah Dasar. JPSD. 4 (1), 102-114

Pujiatna, T. (2018) Penguasaan Ejaan Bahasa Indonesia dalam Kemampuan Menulis Mahasiswa Baru sebagai Bahan Penyusunan Silabus MKU Bahasa Indonesia Universitas Swadaya Gunung Jati Cirebon. Deiksis. 5 (1), 91-99.

Saputra, R. dkk. (2016) Keefektifan Kalimat dalam Karangan Eksposisi Siswa Kelas VIII SMPN 1 Batang Anai. Jurnal Pendidikan Bahasa dan Sastra Indonesia. UNP. 5, 394-400.

Surachman, E. (2016). Workshop Pemanfaatan Media Pembelajaran sebagai Upaya Peningkatan Efektivitas Pembelajaran Serta Profesionalitas Pendidik Di SMP Negeri 194 Jakarta. Sarwahita. 13 (2), 111-119.

UU. Nomor 24 Tahun 2009 tentang Bendera, Bahasa dan Lambang Negara, serta Lagu Kebangsaan.

UU. Nomor 24 Tahun 2009 Pasal 25 ayat 3

UU. Nomor 24 Tahun 2009 Pasal 31 ayat $1 \& 2$

UU. Nomor 24 Tahun 2009 Pasal 31 ayat $1 \& 2$

UU. Nomor 24 Tahun 2009 Pasal 33 ayat 1

UU. Nomor 24 Tahun 2009 Pasal 34

UU. Nomor 24 Tahun 2009 Pasal 36 ayat $1-4$

UU. Nomor 24 Tahun 2009 Pasal 37 ayat $1 \& 2$

UU. Nomor 24 Tahun 2009 Pasal 38 ayat $1 \& 2$ 